NASA TECHNICAL MEMORANDUM

\begin{tabular}{l}
\multirow{1}{*}{} \\
$\frac{1}{x}$ \\
$\frac{1}{2}$ \\
$\frac{1}{2}$
\end{tabular}
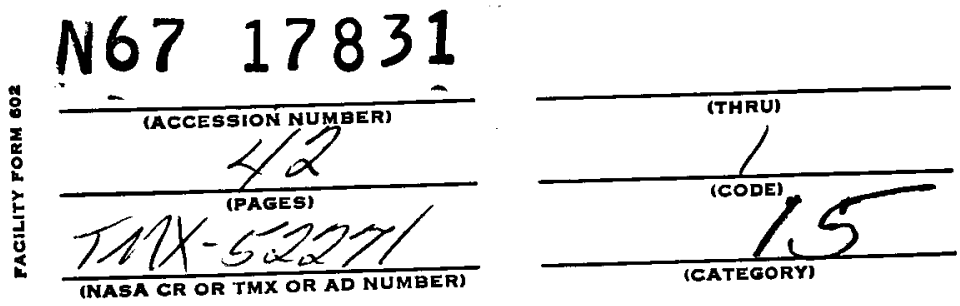

GPO PRICE

s

CFSTI PRICE(S) \$

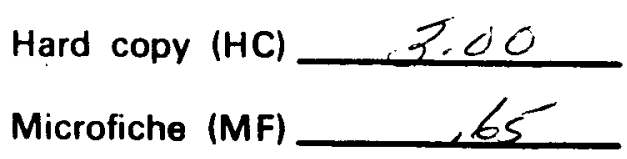

f 653 July 65

NASA TM X-52271

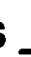

Hard copy $(\mathrm{HC}$

3.00

-

1653 July 65 


\section{LUBRICATION AND WEAR FUNDAMENTALS FOR HIGH VACUUM APPLICATIONS}

by Robert L. Johnson and Donald H. Buckley

Lewis Research Center

Cleveland, Ohio

TECHNICAL PAPER proposed for presentation at

Conference on Lubrication and Wear

Fundamentals and Application to Design

sponsored by the Institution of Mechanical Engineers 


\section{SYNOPSIS}

A review of available literature suggests a correlation between cleavage, adhesion and sliding friction. The proper hexagonal crystal structure and interface contamination can be selected to obtain low friction and reduce surface failure. 


\section{IUBRICATION AND WEAR FUNDAMENTALS FOR HIGH VACUUM APPLICATIONS}

by Robert I. Johnson and Donald H. Buckley

Lewis Research Center

National Aeronautics and Space Administration

Cleveland, Ohio

\section{ABSTRACT}

The problems of lubrication and wear in vacuum are mostly caused by the low pressure and lack of oxygen. Important considerations are (1) inability to maintain oxide films (2) evaporation of lubricants and (3) poor heat transfer. The usefulness of the adhesion concept of friction is demonstrated by correlation of cleavage and adhesion studies with sliding friction. Behavior of solids in these areas of study is significantly influenced by crystal structure and atomic bonding forces. Better definition of surface, lubricating films and slider material on the basis of atomic arrangement in crystals and molecules, is needed for continued progress.

Metals and alloys with hexagonal crystal structure and a c/a stacking ratio approaching ideal (1.633) have useful friction and wear properties. Crystal structures of inorganic lubricants are also important. Adhesion between surfaces in sliding contact may result in junctions formed from (I) diffusion bonding (i.e. solid solubility) (2) chemical bonding and (3) mechanical bonding. Material transfer occurs during sliding with most material combinalions by one or more of these adhesion processes. Properties such as the proper hexagonal structure or contamination films that cause subsequent shearing to occur in the plane and region of the original interface will minimize adhesive wear. Friction responds to factors such as crystal structure that influence the shear strength of metal junctions. 
Methods for maintaining useful surface contamination and obtaining proper crystalline structure are the most promising areas for study in achieving efficient operation of sliding surfaces in vacuum. The problems as well as materials for their solutions need to be defined on the basis of atomic structure.

\section{INTRODUCTION}

The relatively recent extreme interest in mechanical devices to operate in space has provided extensive support for Iubrication friction and wear studies in vacuum. In most cases the effects of vacuum on lubrication are much more significant that those of weightlessness, space radiation, the modest temperature changes or particulate matter (meteroids). The reasons vacuum environment makes lubrication different and more difficult than in air are associated with lack of surface reactants such as oxygen, the absence of adsorbates critical in some lubrication processes, poor heat transfer, and evaporation or dissociation of lubricating materials (refs. I to 10).

oxygen from the atmosphere has a critical role in lubrication, friction, and wear phenomena. The conventional lubrication technology has been developed with oxygen present and having a primary influence on surface chemistry. Much present day lubricated machinery would not run were it not for rcactants and adsorbates from the atmosphere. Even casual experimentation in vacuum quickly shows the dominant role convective heat transfer by the atmosphere plays in dissipating frictional heat. Bearings and other parts run in vacuum under nominal conditions will commonly operate at from $100^{\circ}$ to $200^{\circ} \mathrm{C}$ higher temperature than in air. 
Higher operating temperatures and lower pressures contribute to accelerated loss of lubricating materials by evaporation and dissociation. The most common metal oxides on lubricated parts will not dissociate in vacuum except at extreme temperatures (e.g. FeO $\rightarrow \mathrm{Fe}$ at $10^{-14}$ torr and $1200^{\circ} \mathrm{K}$ ). Once the oxides are worn away, however, they cannot be reformed in vacuum as they are in air. New materials and design concepts are needed for devices that must operate in vacuum. Clever designs to provide hermetically sealed systems can frequently be used to provide a good environment for lubrication. That approach has been successfully used on spacecraft. As the operating duration and severity of mechanical conditions are extended, however, it becomes increasingly important to obtain improved materials for lubrication that can operate completely exposed to space environment.

Surface films such as oxides, adsorbates, etc. are contributing factors to all lubrication studies in the atmosphere. Studies in vacuum offer the opportunity to explore slider materials independent of the surface film effects that are so important in air. Therefore, many criteria of basic importance can be studied in relatively simple experiments to enhance our understanding of friction and wear. The results of vacuum studies can also be applied to more conventional problem areas, however; since one of the steps in the failure of sliders is the rupture of surface films and consequently the exposure of nascent sites on the surface. Materials that function well in vacuum will usually also do well in air but the converse is not so apt to be true. It can be shown for example, that slider alloys formulated for vacuum will function well in diverse problem areas. 
The object of this presentation is to briefly summarize some of the recent important basic observations made by investigators of lubrication related phenomena in the vacuum environment. Primary emphasis is on studies at the authors: laboratory, the NASA-Lewis Research Center. The discussion will touch on vacuum technology, formation and degradation of lubricating films, cleavage studies of lubricating materials, and adhesion of clean materials, as well as friction and wear phenomena.

\section{VACUUM SYSTEMS}

The technology of attaining ultra high vacuum levels of less than $10^{-9}$ torr with clean systems is very recent. The matter of system cleanliness is extremely critical in studies of lubrication, adhesion, friction and wear. Organic contamination in vacuum systems from back migration of diffusion pump oil or evaporation of constituents from elastomer or plastic parts such as seals results in condensation on experimental surfaces. There are instances of nominally unlubricated bearings running thousands of hours without failure in vacuum; it is likely that these systems were contaminated. In some cases, the same parts were subsequently run in more clean, ion pumped systems and failure was experienced in minutes. This is not to say that oil diffusion pumped systems cannot be adequately trapped to eliminate contamination; in much of the published data on lubrication, friction and wear in vacuum, however, a clean system was not likely. Iittle attention will be paid to these data.

The use of ion pumps, liquid nitrogen and liquid helium cryopumping, sorption forepumps, combined with metal seals, chamber bakeout and electron gun specimen bombardment has given clean surfaces in 
NASA-Lewis studies (ref. 4). Mechanical experiments have been performed in the pressure range of $10^{-14}$ to $10^{-9}$ torr with most work now in the 10-11 to 10-10 torr range. Magnetic mechanical drives are used as shown in the friction apparatus of figure 1. That apparatus can also be used for adhesion measurements. Providing a separately pumped support bearing chamber with molecular flow sealing from the specimen chamber improves the vacuum capabilities of such a system from the $10^{-11}$ torr to the $10^{-13}$ torr range. Mass spectrometer partial pressure analyzers indicate that hydrogen is the primary matter present in such vacuum chambers.

Achieving nascent surfaces in friction experiments even in clean vacuum chambers is difficult because of the tenacity and stability of surface reaction films such as oxides. With a typical chromium bearing steel (52100), many sliding traversals are necessary before residual films are worn away such that the friction coefficient changes from approximately 0.5 to 1.0 or greater and eventually to values greater than 20 with seizure ultimately occurring. An electron beam can be used to scrub experimental surfaces; it produces local heating that in combination with the particle energy, causes dissociation of reaction films and even evaporation of some of the substrate metal in hard vacuum ( $<10^{-9}$ torr). The case for tungsten is unusual, the bonding energy for the oxide is greater than for the metal so that substrate metal must be evaporated to achieve clean surface (ref. 11, May).

\section{EVAPORATION}

Evaporation, sublimation and dissociation studies of lubricating materials conducted in laboratories are generally performed under 
conditions such that the greatest possible weight loss and chemical change associated with lubrication problem areas are simulated; such conditions are where no equilibrium vapor pressure exists at the evaporating surface. A reasonable method of measuring evaporation can be based on the work of Langmuir (ref. 6). Where there is no equilibrium vapor pressure the Langmuir equation offers a reasonable basis for calculating evaporative losses in the pressure region of molecular flow and is usually given as follows:

$$
P=17.14 G \sqrt{\frac{T}{M}}
$$

where

G evaporation rate, $\mathrm{g} / \mathrm{sq} \mathrm{cm} / \mathrm{sec}$

M molecular weight

$\mathrm{P} \quad$ vapor pressure, $\mathrm{mm} \mathrm{Hg}$ (torr)

T temperature, ${ }^{\mathrm{O}} \mathrm{K}$

As used to calculate evaporative losses by Hickman (ref. 7) it had the form:

$$
G=5.833 \times 10^{-2} P \sqrt{\frac{M}{T}}
$$

When the vapor pressure of a material is known at one temperature $T$, and its value is desired at another temperature $\mathrm{T}_{2}$, it can be calculated with heats of vaporization and sublimation using the Clausius-Clapeyron equations in their integrated forms (ref. 8):

$$
\log \frac{\mathrm{P}_{2}}{\mathrm{P}_{1}}=\frac{\Delta \mathrm{H}_{\mathrm{V}}}{2.303 \mathrm{R}} \frac{\mathrm{T}_{2}-\mathrm{T}_{1}}{\mathrm{~T}_{1} \mathrm{~T}_{2}}
$$




$$
\log \frac{\mathrm{P}_{2}}{\mathrm{P}_{1}}=\frac{\Delta}{2.303 \mathrm{R}} \frac{\mathrm{T}_{2}-\mathrm{T}_{1}}{\mathrm{~T}_{1} \mathrm{~T}_{2}}
$$

where

$\Delta \mathrm{H}_{\mathrm{v}}$ heat of vaporization

$\Delta \mathrm{H}_{\mathrm{S}} \quad$ heat of sublimation

R gas constant

With a knowledge of heats of vaporization or sublimation and a single vapor pressure, the vapor pressure at other temperatures may be calculated (ref. 8).

There are diverse opinions summarized in reference 5 on the proper way of obtaining and reporting evaporation data. Typically the weight loss measurements in an evaporation experiment would be expected to be several times greater than in a machine part such as a shielded ball bearing where an equilibrium vapor pressure is likely.

Typical evaporation rates from references 5 and 8 for fluid lubricants considered for space devices at $100^{\circ} \mathrm{C}$ and $10^{-7}$ torr are around $10^{-6}$ gram per square centimeter per second (e.g. chlorophenyl methyl polysiloxane); for a plastic (e.g. polytetrafluoroethylene) the rate would be less than 1 percent $\left(10^{-8} \mathrm{gm} / \mathrm{cm}^{2} / \mathrm{sec}\right)$ that of the liquids and for useful metals ( $\mathrm{Ag}, \mathrm{Ga}$ ) or inorganic compounds ( $\mathrm{MoS}_{2}, \mathrm{CaF}_{2}$ ) used in lubricating films the rate would be much less than 0.01 percent $\left(10^{-10} \mathrm{gm} / \mathrm{cm}^{2} / \mathrm{sec}\right)$ of that for the liquids.

\section{CLEAVAGE}

The cleavage studies of mica by A. Bailey (ref. 9, II, p. 409) demonstrated that forces approaching the calculated ionic bond strengths 
in air could be measured. It should be appreciated that mica is unique, however, the ever-present crystal imperfections (dislocations) of most materials make achievement of exact correlation between thecretical bond strengths and experimental cleavage data unlikely. Refinements in vacuum technology and research techniques have allowed other workers (refs. 10, 11, 12, and 13) to do discerning work with cleavable solids. The increasing possibilities of obtaining crystals that have fewer dislocations and other defects (ref. 14) could further enhance the significance of such experimental studies.

Crystal structures with ionic, covalent and/or van der Waals bonding have been examined theoretically (eq. mica, ref. 9, p. 415). The covalent bonding gave greatest strengths and van der Waals bonding the least strengths. Lamellar solid lubricants with van der Waals bonding are among the cleavable solids studied (ref. 13). Most crystals with ionic bonding cleave with difficulty and are not useful as lubricating solids. In general, that binding energy as measured in cleavage studies can be correlated with adhesion and with shearing in sliding friction. Indications of adsorption have been observed after cleavage in vacuum systems (ref. 13). Immediately after cleavage the exposed nascent surfaces adsorbed gases sufficient to measurably reduce the vacuum chamber pressure (rei. 13). THere cain be no doubt that sorption phenomena are extremely important to cleavage and subsequent adhesion as cleaved surfaces reestablish contact. Anomalies found with graphite in measurement of cleavage and shear are probably results of sorbates. 
Many factors are important as the potential uses of data from cleavage studies in engineering applications are considered. Mechanical deformations developed during cleavage cause mismatching of atomic sites or surfaces during renewed contact and contribute to reduction in subsequent cleavage forces. It is the resistance to initial cleavage (also termed tenacity) that determines the ductility of crystalline materials. Materials with low dislocation mobilities show low tenacity (ref. 12). It has been suggested that the plane of minimum surface energy should be the cleavage plane and that predictions of cleavage force can be made if the elastic molulus and surface energy are known (ref. 12). It has been shown that the formation of charge mosaics occur when reversible crack propagation is experienced (ref. 10). Ryan (ref. 1l) found immobile long range attractive forces between freshly cleaved silicate single crystals. These forces were associated with breaking of atomic bonds at the cleaved interface. When contact is reestablished the forces needed for subsequent cleavage were increased with greater loading. This observation was related to the greater atomic bonding forces as atoms on the surfaces are brought into closer proximity.

Most engineering materials are polycrystalline alloys and are so complex as lo defy tho general use of the rational based on atomic bonding forces and resultant charge mosaics. That rational was largely developed with single crystals of materials having properties (i.e. mica) which contributed to ease of interpreting data. Discerning appraisal of these data can, however, help to develop insight that should be increasingly valuable as engineering materials become better defined and more 
nearly perfect crystals are available for study. It would appear that surface structure needs to be characterized on an atomic basis. However, our present capability in atomic characterization of surfaces is inadequate. In the engineering sense it would seem that relatively small benefit is gained from cleavage studies and that shear studies are easier and provide a related but more direct insight for lubrication, friction and wear problems.

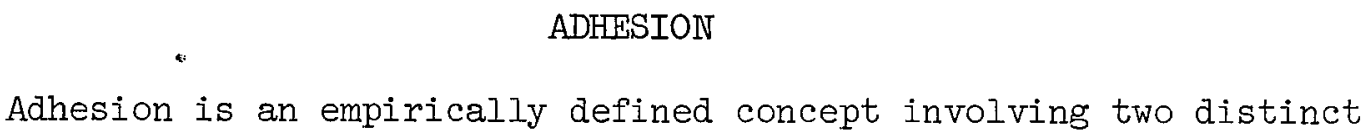
processes. These are (1) the making of an adhesive bond and (2) the fracture of an adhesive bond. The adhesion coefficient is the ratio of the force used to fracture the adhesive bond to the force employed in making the bond. Experimental studies of these phenomena seldom provide the atomically cleaned surfaces that investigators seek in vacuum. One approach to minimize contaminating films has been to fracture solid specimens in vacuum followed by the making of an adhesive bond by bringing the surfaces back together again under load (the first process above). In that case the processes are similar to rejoining of surfaces following cleavage as previously discussed.

It has been shown that adhesion coefficients in addition to being very sensitive to contamination, will also vary with many factors: contact time, separation time, load, shear during load, vibration, and other factors independent of the materials under examination. What then is the real significance of the adhesion coefficient? It would appear that the adhesion coefficient is merely a convenient number. Irivestigators working in the load range of elastic deformation (ref. 16) are 
in a much more difficult area of experimentation than those using loads sufficient to give substantial plastic deformation (ref. 1l, Hordon). When plastic deformation and shear are imposed together (refs. 17 and 18) strong adhesion bonds can easily be established in normal atmosphere. In sliding friction both plastic deformation and shear occur with the consequence that strong adhesive bonds develop.

A measure of contact resistance during adhesion studies has been süggested (ref. 11, Keller) as a means of gaining increased insight. Interpretation of these data suggest that contamination is the only major barrier to adhesion and the release of elastic stresses is not significant in the fracture of metal junctions formed by cold welding. To the contrary, early studies of adhesion (ref. 9, II, Chapter 5) had indicated quite conclusively that release of elastic stresses did, in fact, fracture adhering junctions. The conclusive demonstrations of adhesion with low elastic modulus metals such as indium were not considered by the investigators (ref. 9) to be directly applicable to more common engineering metals. Used in thin films, however, indium can be important to sliding surfaces.

Investigators interested in engineering applications of adhesion studies have emphasized diffusion bonding or solid solubility as the primary mechanism for adhesion. They have used phase diagrams as a guide in selecting metal combinations. The basic parameters considered to contribute to solubility as suggested by Hume-Rothery include atomic size factor and electronegativity. In some instances, encouraging trends have been found but there can be no question that factors other 
than solid solubility are also important (ref. 1l). For example, according to any known guide, metallic calcium should not adhere to iron in a vacuum; the authors of the present paper have, however, observed substantial adhesion and gross metal transfer of calcium to iron. Furthermore, it has been shown that metals having high values of several important factors (elastic moduli, hardness, surface energy, recrystallization temperature, and resistance to plastic flow) can be characterized by low adhesion coefficients without regard for solid solubility.

\section{Lattice Parameters}

It has also demonstrated that cubic structured metals have a greater tendence to adhere than hexagonal structured metals (ref. Il, Buckley). Lattice parameters and orientations are important to adhesion as well as to shear of solid materials. Tables I and II (ref. II, Buckley) give adhesion data for copper single crystals with matched poles to illustrate the significant differences that result from orientation. It should be noted that the adhesion of polycrystalline copper approaches that for the single crystal orientation giving the greatest adhesion. Table III (ref. 1l, Buckley) shows the adhesion behavior of copper-copper and cobalt-cobalt couples with matched poles. The hexagonal cobalt shows much less adhesion than the cubic copper.

In considering experimental results on adherance of nonsoluble couples such as nonmetals (plastics) to metal, the importance of mechanical adhesion becomes apparent. Plastic flow of one material into the surface imperfections of the other creates very strong 
mechanical adhesive bonds. In the process of plastic flow, the softer material may be work hardened to give strengths greater than the original body. Thus, on subsequent separation or shear, fracture may occur in the original body rather than at the interface.

It is likely also that chemical bonds are important in adhesion where compounds are used as contacting solids. Types of bonding that may be considered pertinent to lubrication are (1) diffusion bonding (solid solubility); (2) mechanical bonding; and (3) chemical bonding. There are many factors that determine the forces necessary to separate adhering surfaces and among the most significant of these are contaminating films, structure of material and the chemical thermodynamics of the system involved. The mechanisms occuring during separation or fracture of adhering surfaces can be treated theoretically by different approaches. Reference 15 suggests applicable theories are advancing along three different levels: (1) continuum mechanics; (2) mechanics of microstructures; and (3) atomistic mechanics. Once again the need was suggested for better definition of surfaces and interface phenomena on an atomistic basis. The most likely fruitful areas for study to minimize adhesion in engineering practice are those concerned with sustained contamination or with crystal structure of metals.

\section{FRICTION AND WEAR OF UNLUBRICATED SOLIDS}

The early work of Ernst and Merchant (ref. 19) and the more widely known efforts of Bowden and Tabor (ref. 9) considered adhesion as a primary factor contributing to sliding friction. The greatly 
increased probability of adhesion between solids in a vacuum environment has given added importance to those early studies. The adhesion concept of friction and wear has served well for many years as a primary factor guiding the present authors' research at NASA Lewis Research Center. Therefore, those factors that are important in the simple adhesion at metallic interfaces are also important in the more complex process of sliding friction.

Alloys

In engineering applications it is often necessary to select readily available alloys to use in vacuum. Nonhomogeneous alloys such as tool steels show much better friction and wear characteristics than homogeneous alloys such as austenitic stainless steel (ref. 4). Also, recast alloys with large grain size have somewhat better friction behavior than the original forged alloys. Surface welding can be inhibited by providing alloys with microinclusions of stable compounds capable of smearing over the slider interface as the original surface films (e.g. oxides) are removed (ref. 4). For example, 0.45 percent sulfur present as iron sulfide in electrolytic iron or tool steels inhibited surface welding and grossly reduced wear or friction or both. Similar effects were gained with nickel oxide or tin in nickel when duplex structures were achieved.

Solid Solubility and Polymorphism

The rare eurth metals (ref. 20) merit special consideration for vacuum problems. The oxides are chemically very stable and, in accordance with the Hume-Rothery rules, the metals should have little or no solubility in ferrous alloys. Rare earth metals have been shown to have adhesion coefficients that are less than 1/10 that for 
other soft metals such as lead, tin or indium with iron (ref. 17). Further, numerous rare earth metals that normally have hexagonal structure undergo crystal transformation to cubic structures at rather low temperatures and hence offer convenient materials to use in determining the relative merit of solid solubility and crystal structure as basic properties in selecting slider alloys. For example, lanthanum is hexagonal at room temperature but develops a face centered cubic structure above $200^{\circ} \mathrm{C}$.

Friction studies were therefore made with lanthanum under conditions where crystal transformation would take place. Figure 2 shows the effect of increasing sliding velocity on friction for lanthanum sliding on itself in vacuum. At increasing sliding velocities, and therefore greater surface temperatures, friction coefficient changed from 0.35 to 1.4 when the hexagonal to cubic transformation occurred. On cooling to the solid condition, the friction that is characteristic of the hexagonal lanthanum was observed showing that the effect was reversible. Data were also obtained with lanthanum over ranges of loads, temperatures and sliding velocities; with each variable, similar friction transitions were found. Also, when lanthanum was in the cubic form, it showed gross metal transier to stcel and high wear while hexagonal lanthanum gave little metal transfer and low wear. These observations were typical for the hexagonal rare earth metals. It should be specially noted that gross metal transfer occurred in spite of negative solid-solubility parameters in the cubic metal and that a metal transfer problem was 
not experienced with the same metal (no change in solubility parameters) when used in the hexagonal form.

Thallium is another hexagonal metal that has a low temperature crystal transformation. As shown in figure 3, data obtained with thallium were similar to that for lanthanum. At the highest sliding velocity, surface melting gave very low friction. After cooling the entire specimen to room temperature, friction was similar to that initially measured.

Hexagonal Metals

Room temperature data were obtained for a series of hexagonal metals in addition to the rare earth metals. Figure 4 shows that the friction can be related to the ratio of the interbasal planar spacing (usually the parameter $c$ ) to the parameter a, the distance between atoms in the basal plane of the hexagonal lattice. The observed friction is considered to be related to slip mechanisms within the crystals. Those metals possessing a c/a ratio near the ideal for hexagonal close packing (1.633) slip primarily on the basal plane (0001). With a single slip plane, relatively low shear forces are needed. Beryllium has a basal slip mechanism despite its lattice parameters because its atomic size results in less interbasal bonding forces than hexagonal metals with comparable c/a ratios. Metals deviating from the ideal ratio, slip on other planes, in addition to the basal planes. Titantium for example, slips on the prismatic (1010) plane and, to a lesser extent, on pyramidal planes (ref. 2I). Alloys of titanium were made in an attempt to provide more nearly ideal stacking $(c / a)$ ratios for achieving basal plane slip. 
Figure 5 shows the influence of aluminum and tin additions to titanium on the lattice ratio, c/a, and on friction. The lattice parameters were determined by $\mathrm{X}$-ray diffraction methods. These data also conform to the trend of friction as a function of lattice parameters in figure 4. As the c/a ratio increased, the friction coefficient decreased along with reductions in wear and galling tendencies.

As figure 6 shows, unalloyed cobalt in the low temperature hexagonal form has good friction and wear properties but becomes progressively worse as the metal was transformed to the face centered cubic structure. Alloying was also used to stabilize the crystal structure of cobalt (ref. 22). Alloying of cobalt with 25 percent molybdenum stabilized the hexagonal structure with no significant change in c/a ratio. That alloy had essentially the same low temperature friction as hexagonal (unalloyed) cobalt but did not show any change in friction at temperatures to $700^{\circ} \mathrm{C}$. Slip Planes and Directions

Single crystal and polycrystalline material of varied crystal types have been explored to determine the influence of slip planes and slip direction on friction properties. As sliding progresses from one crystal to the next in a polycrystalline material, there is a corresponding change in friction. These changes reflect the different slip systems on the various crystallites. Further, on any particular plane a change in sliding direction results in a change in friction. Figure 7 shows data obtained with a specimen of tungsten (ref. 23) having a series of large crystals that had been characterized using X-ray Laue' back reflection. The data (fig. 7) 
show the influence of: (1) surface films (oxides); (2) changing slip systems while crossing grain boundaries; and (3) the sliding direction on a crystallite. The data in air reflect the varied oxidation properties of the different crystal faces. Also, there is a correlation between hardness on the (100) plane and friction; friction decreases with greater hardness. These data on tungsten and that on additional metals and other materials (refs. 23, 24 and 25) show that the friction coefificient is lowest for the greatest atomic density planes and when sliding in the preferred slip direction (the direction of greatest atomic density).

Another factor concerning atomic arrangement that influences those physical properties having a bearing on friction is the ordering of the atoms in alloys. With special systems such as $\mathrm{Cu}_{3} \mathrm{Au}$ it was found that order-disorder reactions influence friction behavior in vacuum (ref. 23). Low friction was observed for the ordered state while high friction and complete welding was found for the disordered state.

Chemical Bonding

It has been demonstrated that chemical bonding can be a determining factor in friction (ref. 26). Friction experiments were conducted with various metals sliding on single and polycrystalline $\left.{ }^{A}\right]_{2} \mathrm{O}_{3}$ and the results obtained are presented in figure 8 (ref. 26). With five different metals sliding on sapphire, the friction coefficient was approximately the same (fig. 8). With all of the metals, fracture or cleavage occurred in the sapphire accounting for the similiarity in friction. Chemical bonding and 
adhesion of the metals to the sapphire resulted in stresses and fracture in the sapphire as indicated for beryllium sliding on sapphire in the photo insert. In some instances the pits in sapphire were o $250 \mathrm{~A}$ in depth.

With various metals sliding on polycrystalline aluminum oxide, much higher coefficients of friction were observed (fig. 8). The surfaces of the polycrystalline $\mathrm{Al}_{2} \mathrm{O}_{3}$ disks all indicated transfer of metal to the disk surface. The transferred metal on $\mathrm{Al}_{2} \mathrm{O}_{3}$ is shown in figure 8 for aluminum and zirconium. While with metals sliding on sapphire, fracture occurred in the sapphire; in contrast with metals sliding on polycrystalline $\mathrm{Al}_{2} \mathrm{O}_{3}$ shear of the metal was responsible for friction. For the cubic metals the friction coefficients are what might be predicted from the $\mu=\mathrm{S} / \mathrm{H}$ relation (friction coefficient $=$ shear strength/yield strength in compression). Since the metal is shearing and the disk surface is not undergoing notable plastic deformation (to markedly increase the true contact area) these values are as might be anticipated.

The friction data for the hexagonal metals are markedly less than for the cubic metals with one notable exception, namely titanium. These differences in friction characteristics for cubic and hexagonal metals can be attributed to the differences in slip behavior in plastic deformation for hexagonal and cubic metals.

The difference in friction behavior of titanium from other hexagonal metals that slip predominantly on basal planes such as cobalt, beryllium rhenium and lanthanum is that titanium slip primarily on 
prismatic planes during plastic deformation. Thus, greater contact area and increased shear strength can result for titanium with sliding resulting in it behaving more like a cubic than hexagonal metal. Orientation

Sliding of metals usually accomplishes orientation or texturing of the surface layer such that shear continues to develop on the plane of minimum shear strength. Such texturing may be accomplished by plastic deformation or recrystallization, followed by texturing. In order to prevent surface recrystallization, single crystal studies of friction must be conducted at conditions providing a very low rate of friction heating (Iow speeds and loads). Sliding of polycrystalline materials seldom gives the same friction as with single crystals. Even with the desired orientation, dislocation pile-ups at the grain boundaries would impede slip. Such an observation would suggest that slider materials with large grains should give lower friction that materials with fine grains.

\section{FRICTION AND WEAR WITH LUBRICATING FILMS}

Organic lubricating films exposed directly to hard vacuum will not lubricate for more than a few hours at modest temperature because of evaporation (refs. 3 and 27). Further, loss of the more volatile and lower surface tension constituents of organic liquid films in vacuum will reüuce spreadability of the film. In noncirculating systems the reduced spreading ability increases tendency toward lubrication failure. High spreadability may increase evaporation loss of the lubricant if spreading barriers (low surface energy films) are not used. 
21 .

Organic plastic materials such as polyimide or polytetrafluoroethylene have been useful in vacuum for films and solid friction materials (refs. 4 and 9, Chapters 13 and 27). Such plastics develop transfer films on mating surfaces by the mechanical adhesion process. Subsequently they slide against a very thin film of the same composition as the parent body or film. The polyimide has extremely low evaporation in vacuum at temperatures under $300^{\circ} \mathrm{C}$. With 20 weight percent copper fiber in the polyimide, Iriction coefficient in vacuum against hard martenistic stainless steel was less than 0.1 . The copper fibers were incorporated to improve heat transfer.

Several inorganic compounds have low volatility and can serve well as lubricants in vacuum. In general those compounds that depend on absorbates for their lubricating function (such as graphite) are the exception and should not be used in vacuum. Sorbtion phenomena can be explored very nicely in cleavage studies (refs. 10 and 13). Molybdenum disulfide has excellent properties for use as a lubricant in a vacuum environment. It does not depend on adsorbates for its lubricating capabilities and in fact performs best when there is a complete lack of external contamination. MoS 2 data shows good correlation of cleavage, adhesion and shear properties in vacuum (refs. I, $4,5,8,9,10, \overline{15}$, and 27 ) aiild therc are many ways of using the material in engineering applications. Some of the proposed uses of $\mathrm{MoS}_{2}$ in sintered metal bodies have been misleading in that the chemical thermodynamics of the materials and process are such that the MoS $_{2}$ is reduced and other metallic sulfides are formed. Most other uses of 
$\mathrm{MoS}_{2}$ as a lubricant are effective when organic contamination is avoided. The use of $\mathrm{MoS}_{2}$ in polytetrafluoroethylene is of questionable value to lubrication. The friction characteristics obtained are good but are the same as those of the polymer alone. Recently, coatings of $\mathrm{MoS}_{2}$ were achieved in our laboratories in a vacuum system using sputtering. The composition of the film was verified by $\mathrm{X}$-ray diffraction as the compound $\mathrm{MOS}_{2}$ with no indication of elemental molybdenum or sulfur. This film achieved good endurance and low friction (ref. 28). Sodium silicate bonded MoS $_{2}$ films have good performance in vacuum. Other compounds such as $\mathrm{WS}_{2}$ or $\mathrm{WSe}_{2}$ have been suggested for vacuum lubricants and in special applications may offer some improvements (ref. 29). The benefits are marginal in most cases and since the use of $\mathrm{MoS}_{2}$ is more highly developed than for the other compounds, it is good judgment to use $\mathrm{MoS}_{2}$ for vacuum lubrication.

Thin metal platings of gold and silver have been used as lubricating coatings on bearings, electric contacts and other type surfaces (ref. 3) for vacuum environments. The use of thin films on harder substrates can compensate for some of the problems in using the soft or mechanically weak film material as a structural member (ref. 9). With thin films the bond between the coating and its substrate is critical to performance as a lubricant. Ion plating, in vacuum achieves excellent coating adherance and uniform deposition on surfaces with complex geometries (ref. 30). Those methods are also applicable to deposition of alloy films. 
The metal gallium is a material that has promise for lubrication in vacuum (ref. 31). It has a very broad liquidus range, low vapor pressure and has conductivity to suggest usefulness for sliding electric contacts in vacuum. Gallium is a liquid near room temperature $\left(\mathrm{mp} .30^{\circ} \mathrm{C}\right)$ and can be alloyed to form eutectics of lower melting points. The ability of gallium to wet surfaces is critical in lubrication. It has been found that, in spite of reports to the contrary (ref. 15), many clean materials are readily wet by gallium; in some instances mechanical activation (rubbing) hastens the process. Those materials include nickel, copper, aluminum, magnesium, mica and sapphire. The problems in the use of gallium as a lubricant are mostly associated with selection of contacting materials to avoid corrosion. Gallium has also been used in composite materials (ref. 29). APPLICATION OF CONCEPTS TO PROBLEMS IN SPACE DEVICES Specific data on friction surfaces from space flights are sparse. Considering the fragmentary information available, however, some suggestions can be made on possible application of several of the concepts discussed herein. Proprietary interests dictate that specific references be avoided.

Failures of bearing surfaces have been associated with loss of internal clearance as a result of inẩequate appreciation of heat dissipation problems in vacuum. The increased temperature levels, resulting from poor heat transfer, accelerate evaporation of organic fluids and the loss of volatile low surface tension constituents reduces spreadability. Thus lubrication failure can occur before the 
bulk of the fluid is evaporated but when the fluid becomes sufficiently immobile to repair local film failure. Molecular flow seals have been very effective in retarding lubricant loss at modest temperatures $\left(<100^{\circ} \mathrm{C}\right)$.

Organic fluids have been used in conjunction with solid lubricants with apparent success in some applications. The results may be misleading since these applications involved mechanical conditions that may not have required any lubrication. We consider the combined use of organic fluids with solid films as poor practice.

Many uses of bonded $\mathrm{MoS}_{2}$ films without contamination have met with apparent success. In one case, exposure of a sodium silicate bonded $\mathrm{MoS}_{2}$ film to high humidity prior to launch may have resulted in surface adhesion by frozen moisture during a critical low temperature portion of the initial flight period. It should be noted that, under most conditions, sodium silcate bonded coatings give excellent performance and good endurance.

Hinges and pivots of manned flight spacecraft have caused problems because of "cold welding" or adhesion. Even titanium which is commoniy used for flight equipment can be improved to eliminate the galling problem by alloying with aluminum to obtain increased c/a lattice ratio (fig. 5). Bail bearings, seals, gcors and other narts can be made of hexagonal cobalt alloys to avoid catastrophic failure in the event the lubricant films are penetrated. These alloys should also be useful in a wide range of engineering applications in the earths' atmosphere. 


\section{CONCLUDING REMARKS}

The adhesion concepts of friction are especially applicable to problems of lubrication in vacuum. Correlation of experimental observations suggests a direct relation between cleavage, adhesion and sliding friction. Such correlation should be anticipated where the adhesion concepts of friction are applicable.

The surface, surface films and bulk materials must be defined and the shear process studied on an atomic basis. It has been shown that crystal structure parameters, and other atomistic considerations can be used effectively in achieving low friction and wear in the vacuum environment. The vacuum environment is ideal for study of fundamental material factors in sliding friction because contaminating film effects, which usually dominate the friction process, can essentially be eliminated.

Contamination of surfaces to prevent strong adhesive bonding in the vacuum environment is an important approach to achieving minimum friction in mechanical devices. The basic chemistry and physics of contaminating films must also be defined and developed on an atomic basis.

Numerous materials and processes can be suggested to minimize friction probiems in vacuum. In general, the results are also applicable to the less demanding environments of more conventional applications. 
REF'EREIVES

1. Jackson, E. G.: "Lubrication in Space Vehicles," Wear, vol. 5, no. 6, November/December, 1962, pp. 417-434.

2. Goetzel, C. G. ; Rittenhouse, J. B. ; and Singletary, J. B. : Space Materials Handbook, Addison-Wesley Publ. Co., 1965.

3. Johnson, R. L. ; and Anderson, W. J. : "Summary of Lubrication Problems in Vacuum Environment," Proceedings of the 1963 USAF Aerospace Fluids and Lubricants Conference, San Antonio, Texas, April 16-19, 1963.

4. Johnson, R. I. ; Buckley, D. H. ; and Swikert, M. A. : "Studies of Lubricating Materials in Vacuum," Proceedings of the 1964 USAF and Southwest Research Institute Aerospace Bearing Conference, San Antonio, Texas, March 25-27, 1964.

5. Johnson, R. L. ; and Buckley, D. H. : "Lubricants and Mechanical Components of Lubrication Systems for Space Environment," Lubrication Engineering, vol. 22, no. 10, October, 1966, pp. 408-414.

6. Langmuir, I.: "The Vapor Pressure of Metallic Tungsten," Physical Review, ser. 2, vol. 2, no. 5, November, 1913, pp. 329-342.

7. Hickman, K. C. D.: "High-Vacuum Short-Path Distillation - A Review," Chemical Review, vol. 34, no. 1, February, 1944, pp. 51-106.

8. Buckley, D. H. ; and̄ Johnsuri, R. L. : "Evaporation Rates for Various Organic Liquid and Solid Iubricants in Vacuum to $10^{-8}$ Millimeter of Mercury at $50^{\circ}$ to $1100^{\circ} \mathrm{F}$," NASA TN D-208I, December, 1963.

9. Bowden, F. P.; and Tabor, D.: The Friction and Lubrication of Solids, Part II, Oxford University Press, 1964; also Part I, 1950. 
10. Bryant, P. J.; Taylor, L. H. ; and Gutshall, P. L. : "Cleavage Studies of Lamellar Solids in Various Gas Environments," Transactions of the Tenth National Vacuum Symposium, American Vacuum Society, 1963, p. 2l; also Wear, vol. 7, no. 2, March/April, 1964, pp. 118-126 and Proceedings of the Physical Electronics Conference, Massachusetts Institute of Technology, 1966.

11. Anon.: Proceedings of the ASTM-ASIE Symposium on Adhesion in Space Environments, Toronto, Canada, May 1-2, 1967, American Society for Testing and Materials, 1967.

12. Gilman, J. J.: "Cleavage, Ductility and Tenacity in Crystals," Fracture, Proceedings of an International Conference on the Atomic Mechanisms of Fracture, B. L. Averbach, D. K. Filbeck, G. T. Hahn, and D. A. Thomas, eds., Technology Press of M. I. T., John Wiley and Sons, Inc., and Chapman and Hall, 1959, ch. 2.

13. Haltner, A. J.: "Friction and Wear Characteristics of Materials Under Ultrahigh Vacuum and High Temperature Conditons," ASLE Transactions, vol. 8, no. 2, April, 1965, pp. 133-145.

14. Tyson, W. R.: "Theoretical Strength of Perfect Crystals," Philosophical Magazine, vol. 14, no. 131, November, 1966, pp. 925-936.

15. Salomon, G.: "Adhesion," Adhesion and Adhesives, R. Houwink and G. Salomon, eảs., Amcrican Filsevier, 1965, vol. 1, ch. 1.

16. Keller, D. V.: "Adhesion Between Solid Metals," Wear, vol. 6, no. 5, September/October, 1963, pp. 353-365. 
17. Keller, D. V. : "Application of Recent Static Adhesion Data to the Adhesion Theory of Friction," presented at the 13th Sagamore Conference on Physical and Chemical Characteristics of Surfaces and Interfaces, Syracuse University, New York, 1966.

18. Sikorski, M. E.: "The Adhesion of Metals and Factors that Influence It," Wear, vol. 7, no. 2, March/April, 1964, pp. 144-162; also Journal of Basic Engineering, vol. 85, no. 2, June, 1963, pp. 279285 and ASLE Transactions, vol. 7, no. 1, January, 1964, pp. 73-81.

19. Ernst, H.; and Merchant, M. E.: "Chip Formation, Friction and Finish," The Cincinnati Milling Machine Co., August 24, 1940.

20. Buckley, D. H. ; and Johnson, R. L.: "Influence of Crystal Structure on Friction Characteristics of Rare-Earth and Related Metals in Vacuum to $10^{-10} \mathrm{~mm}$ of Mercury," ASLE Transactions, vol. 8, no. 2, April, 1965, pp. 123-132.

21. Buckley, D. H. ; Kuczkowski, T. J.; and Johnson, R. L.: "Influence of Crystal Structure on the Friction and Wear of Titanium and Titanium Alloys in Vacuum," NASA TN D-2671, March, 1965; also NASA TN D-2988, September, 1965.

22. Buckley, D. H. ; and Johnson, R. L. : "Marked Influence of Crystal Structure on the Friction and Wear Characteristics of Cobalt and Cobalt Base Alloys in Vacuum to $10^{-9}$," I "Polycrystalline and Single Crystal Cobalt," NASA TN D-2523, December, 1964; also II "Cobalt Alloys," NASA TIN D-2524, December 1964. 
23. Buckley, D. H.: "The Influence of Various Physical Properties of Metals on their Friction and Wear Behavior in Vacuum, " presented at the Metal Congress, American Society for Metals, Chicago, Illinois, October 31 - November 4, 1966.

24. Bowden, F. P. ; and Hanwell, A. E.: "Friction and Wear of Diamond in High Vacuum," Nature, vol. 201, no. 4926, March 28, 1964, pp. 12791281.

25. Bowden, F. P.; Brooks, C. A. ; and Hanwell, A. E.: "Anisotropy of Friction in Crystals," Nature, vol. 203, no. 4940, July 4, 1964, pp. 27-30.

26. Buckley, D. H.: "Friction Characteristic in Vacuum of Single and Polycrystalline Aluminum Oxide in Contact with Themselves and with Various Metals," to be published in ASLE Transactions, 1967.

27. Brown, R. D. ; Burton, R. A. ; and Ku, P. M. : "Long-Duration Lubrication Studies in Simulated Space Vacuum," ASLE Transactions, vol. 7 , no. 3 July, 1964, pp. 236-248.

28. Spalvins, T.; and Przybyszewski, J. S.: "Sputtered Molybdenum Disulfide Films as Iubricants in Vacuum," Proposed NASA Technical Note.

29. Boes, D. J.: "Unique Solid Lubricating Materials for High Temperature Air Applications," ASTLE Freprint 66-IC-3, October, 1966; also Bowen, P. H. : "Dry Lubricated Bearings for Operation in a Vacuum," ASLE Transactions, vol. 5, no. 2, November, 1962, pp. 315-326. 
30. Spalvins, T.; Przybyszewski, J. S.; and Buckley, D. H.: "Deposition of Thin Films by Ion Plating on Surfaces Having Various Configurations," NASA TN D-3707, November, 1966.

31. Buckley, D. H.; and Johnson, R. L.: "Gallium-Rich Films on Boundary Lubricants in Air and in Vacuum to $10^{-9}$ Millimeters of Mercury," ASLE Transactions, vol. 6, no. 1, January, 1963, pp. 1-11; also NASA TN D-2721, March, 1965. 


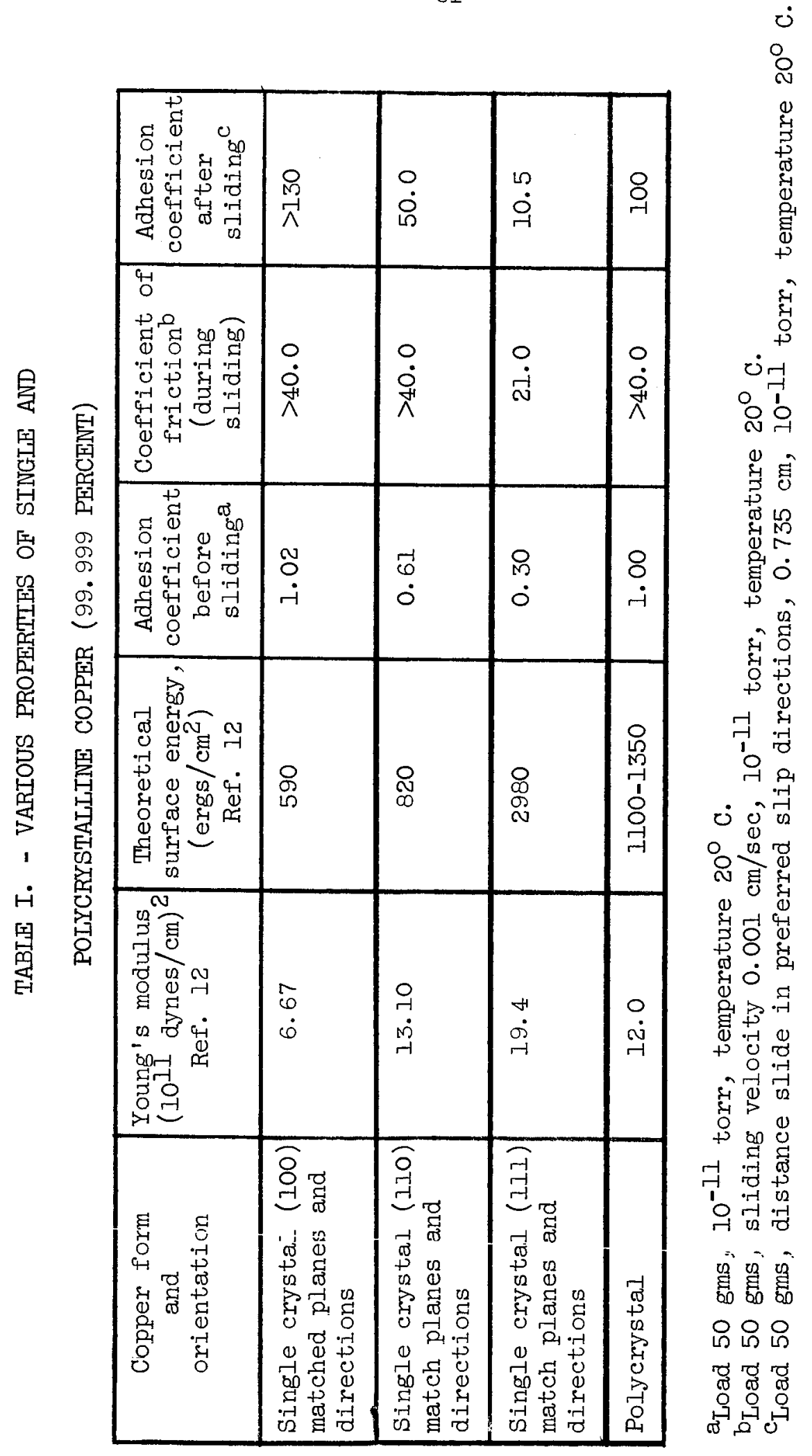


TABLE II. - COEFFICIENTS OF ADHESION AND FRICTION FOR

VARIOUS SINGLE CRYSTAL ORIENTATIONS OF

COPPER (99.999 PERCENT) $\left(10^{-11}\right.$ TORR $\left.20^{\circ} \mathrm{C}, 50 \mathrm{GMS}\right)$

\begin{tabular}{|l|c|c|c|}
\hline Matched planes & $\begin{array}{c}\text { Adhesion coefficient } \\
\text { before sliding }\end{array}$ & $\begin{array}{c}\text { Coefficient of } \\
\text { friction } \\
\text { (during } \\
\text { sliding) }\end{array}$ & $\begin{array}{c}\text { Adhesion coefficient } \\
\text { after sliding }\end{array}$ \\
\hline$(100) /(100)$ & 1.02 & $>40.0$ & $>130$ \\
\hline$(110) /(100)$ & 0.25 & $>40.0$ & 32.5 \\
\hline$(111) /(100)$ & 0.20 & $>40.0$ & 40.0 \\
\hline
\end{tabular}

asliding velicity $0.001 \mathrm{~cm} / \mathrm{sec} ;$ [110] direction; sliding distance $0.735 \mathrm{~cm}$. 
TABLE III. - COEFFICIENTS OF ADHESION AND FRICTION FOR

COPPER (99.999 PERCENT) AND COBALT (99.99 PERCENT) SINGLE CRYSTALS IN VACUUM $\left(10^{-11}\right.$ TORR $)\left(50 \mathrm{GMS}, 20^{\circ} \mathrm{C}\right)$

\begin{tabular}{|l|c|c|c|}
\hline $\begin{array}{c}\text { Metal couples } \\
\text { (matched poles) }\end{array}$ & $\begin{array}{c}\text { Adhesion coefficient } \\
\text { before sliding }\end{array}$ & $\begin{array}{c}\text { Friction coefficient } \\
\text { (during sliding) }\end{array}$ & $\begin{array}{c}\text { Adhesion } \\
\text { after } \\
\text { sliding }\end{array}$ \\
\hline$\frac{\mathrm{Cu}(111)[110]}{\mathrm{Cu}(111)[110]}$ & 0.30 & 21.00 & 10.50 \\
\hline$\frac{\mathrm{Co}(0001)[11 \overline{2} 0]}{\mathrm{Co}(0001)[11 \overline{2} 0]}$ & $<0.05$ & .35 & $<0.05$ \\
\hline
\end{tabular}




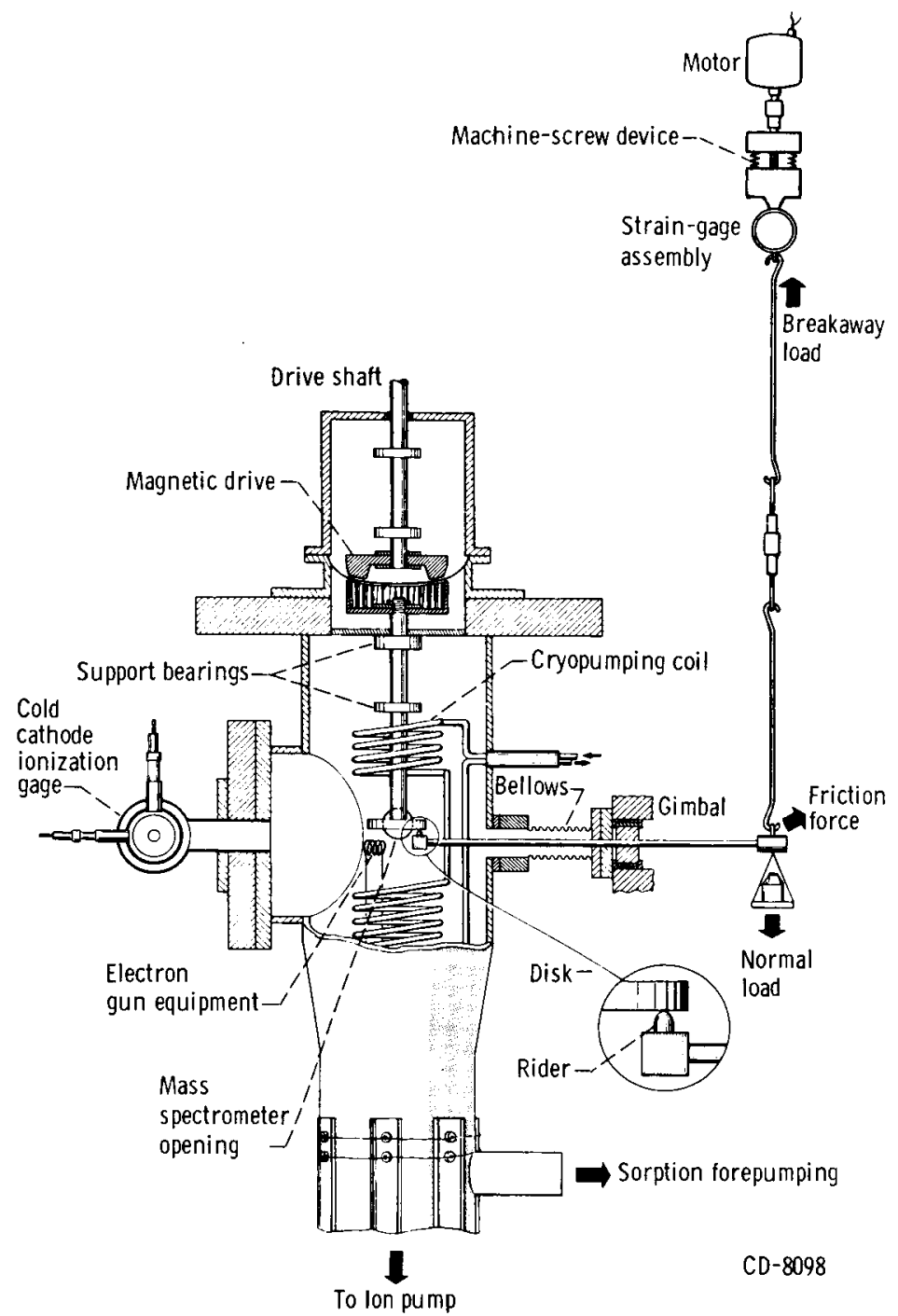

Figure 1. - Vacuum friction apparatus. 


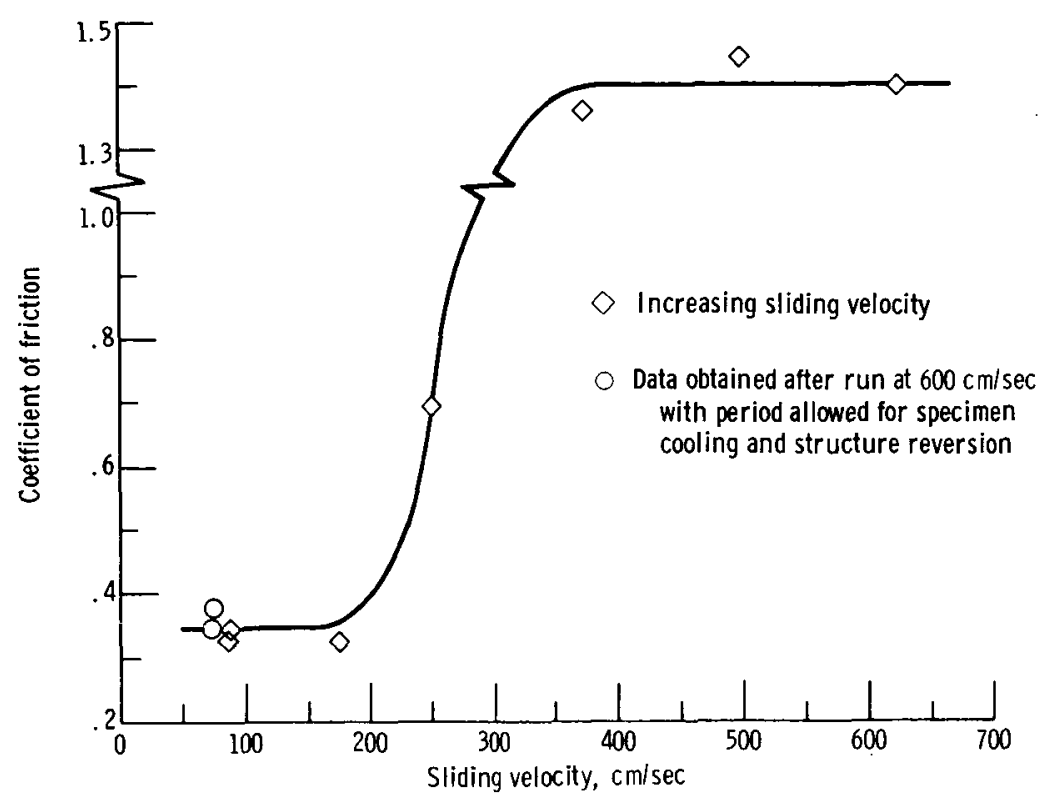

Figure 2. - Coefficient of friction for lanthanum sliding on lanthanum at various sliding velocities in vacuum $\left(10^{-9} \mathrm{~mm} \mathrm{Hg}\right)$. Load, 500 grams; ambient temperature, $20^{\circ} \mathrm{C}$.

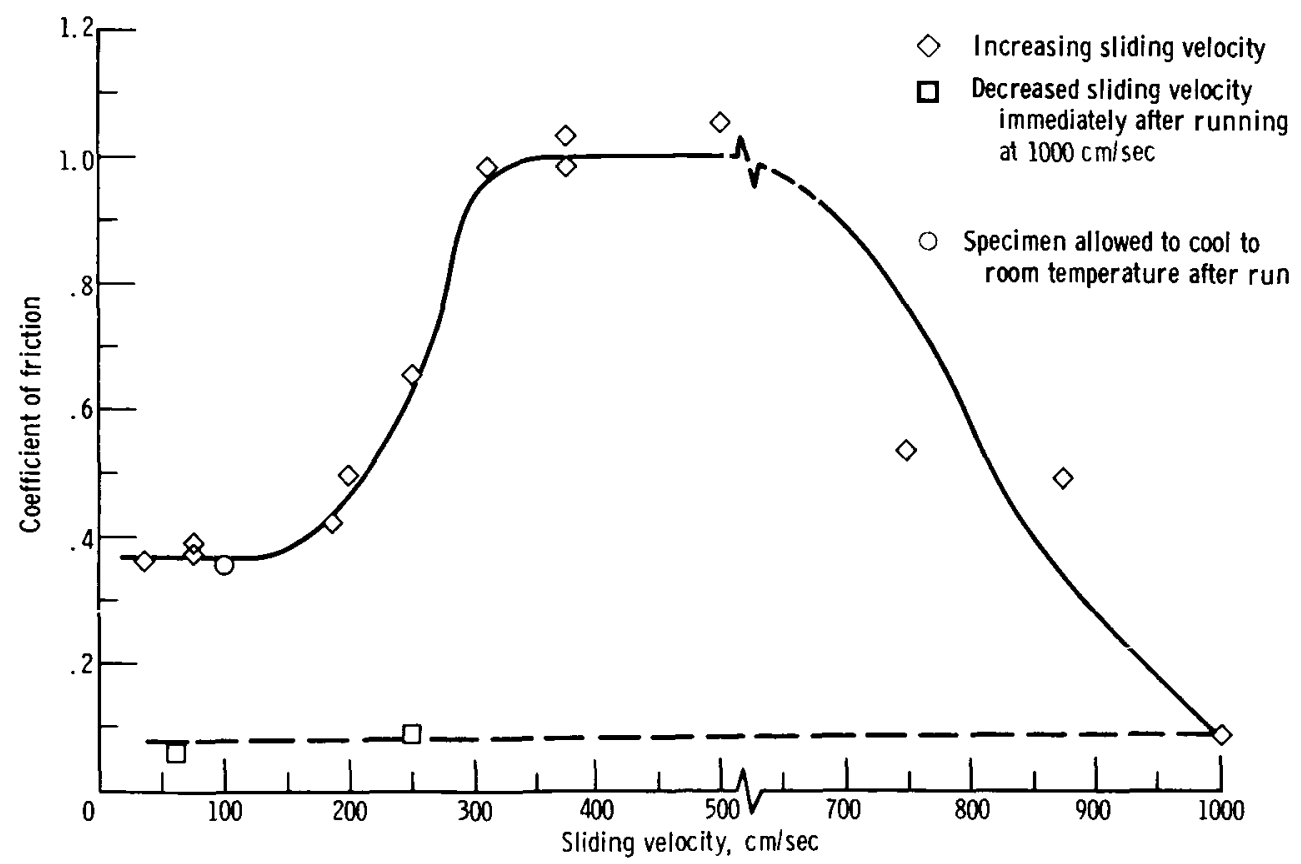

Figure 3. - Coefficient of friction for thallium sliding on $440-\mathrm{C}$ stainless steel in vacuum $\left(10^{-10} \mathrm{~mm} \mathrm{Hg}\right)$. Load, 1000 grams; ambient temperature, $20^{\circ} \mathrm{C}$. 


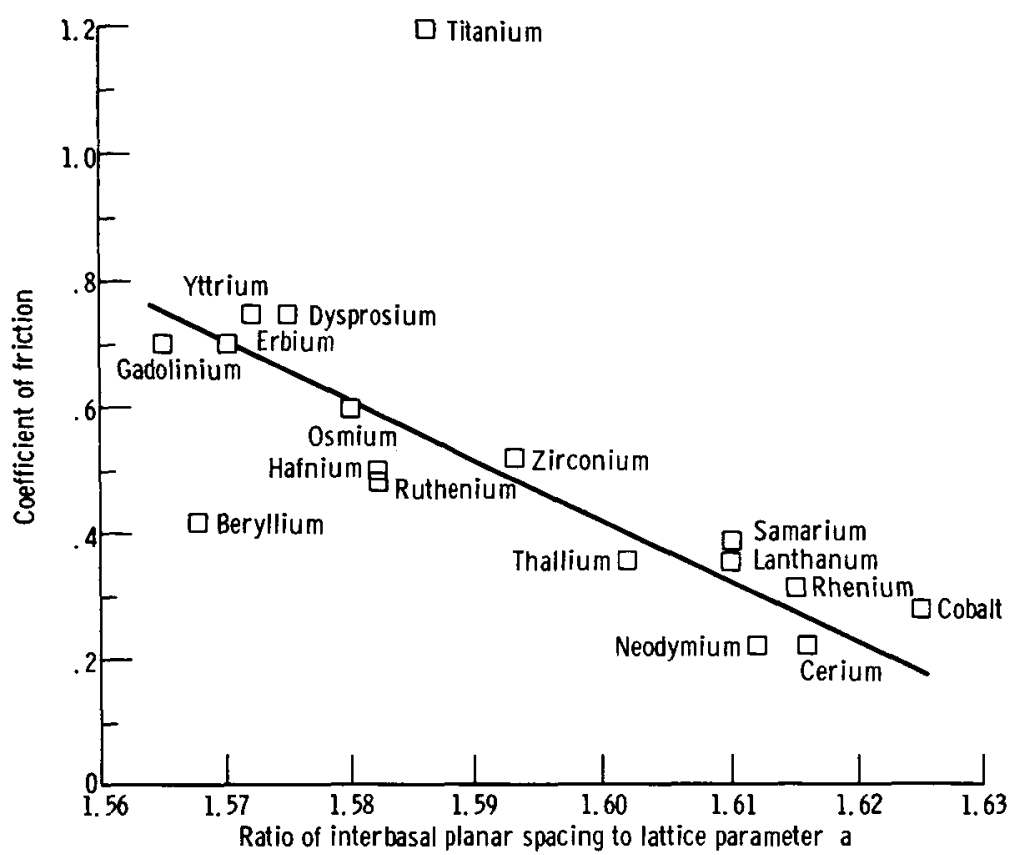

Figure 4. - Friction coefficients for various hexagonal metals sliding on $440-\mathrm{C}$ in vacuum $\left(10^{-9}\right.$ to $10^{-11}$ Torr). (1000 gms, $200 \mathrm{~cm} / \mathrm{sec}$, with no external heating) 
$n$
0
1
1
1
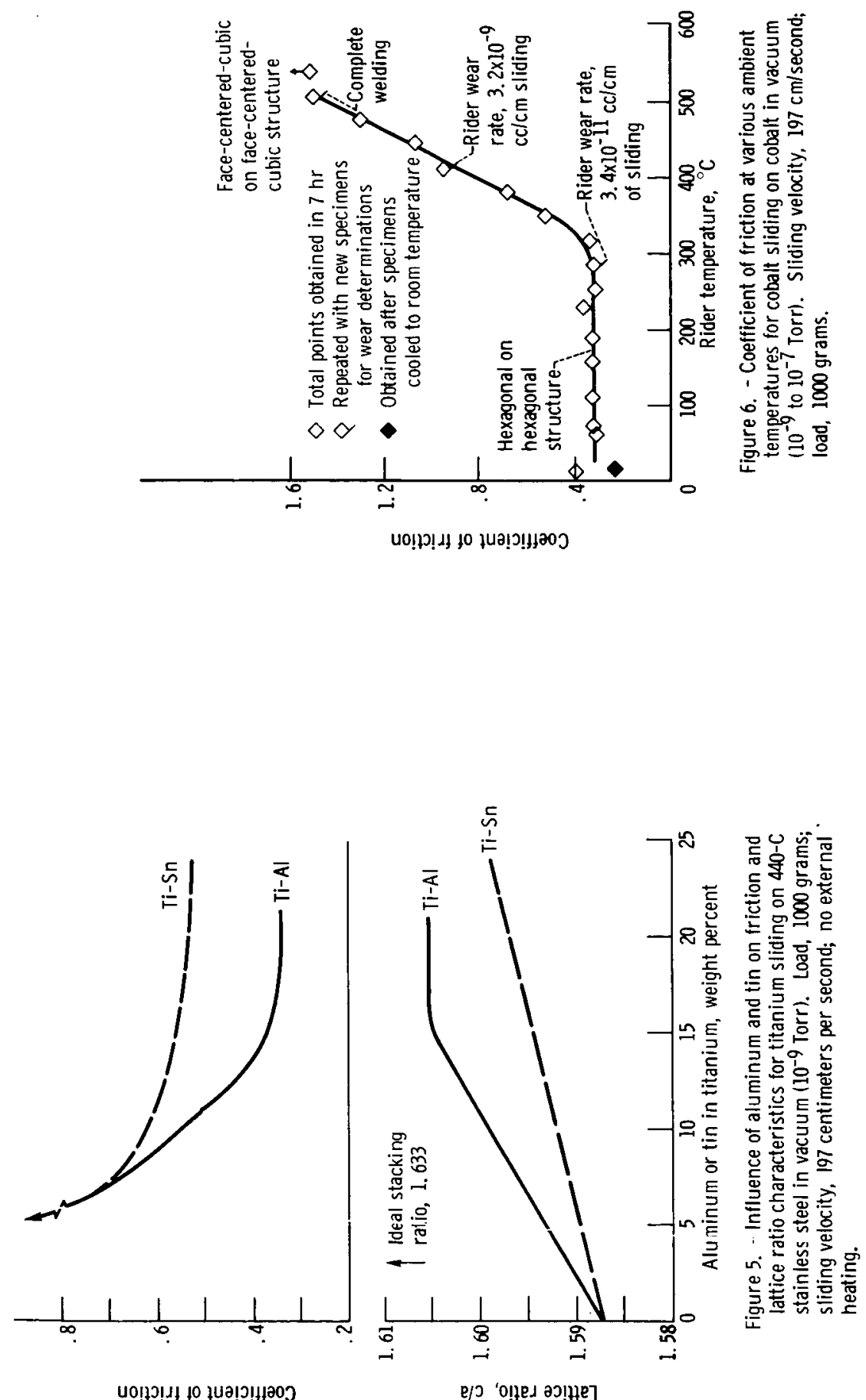

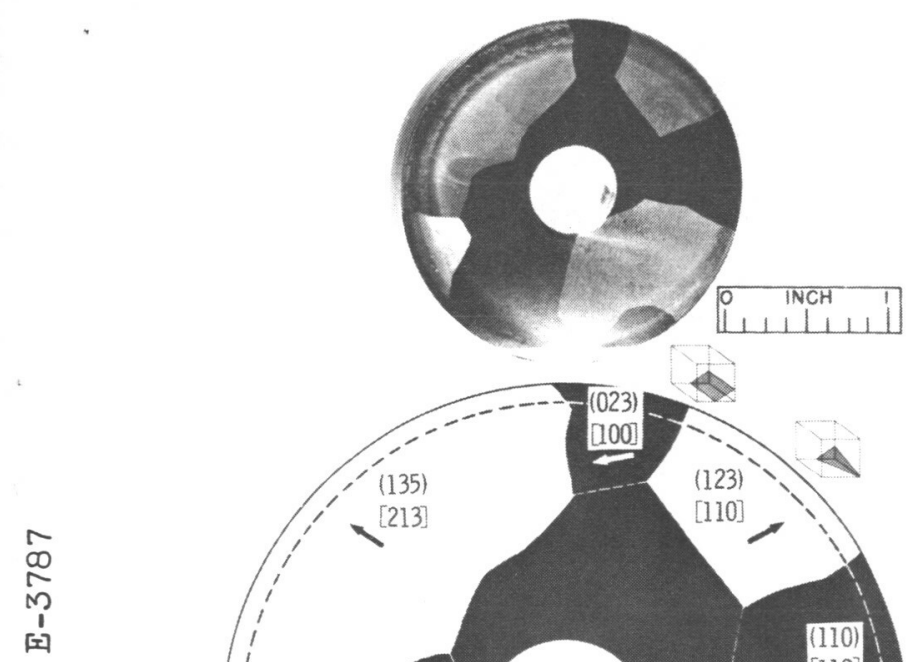

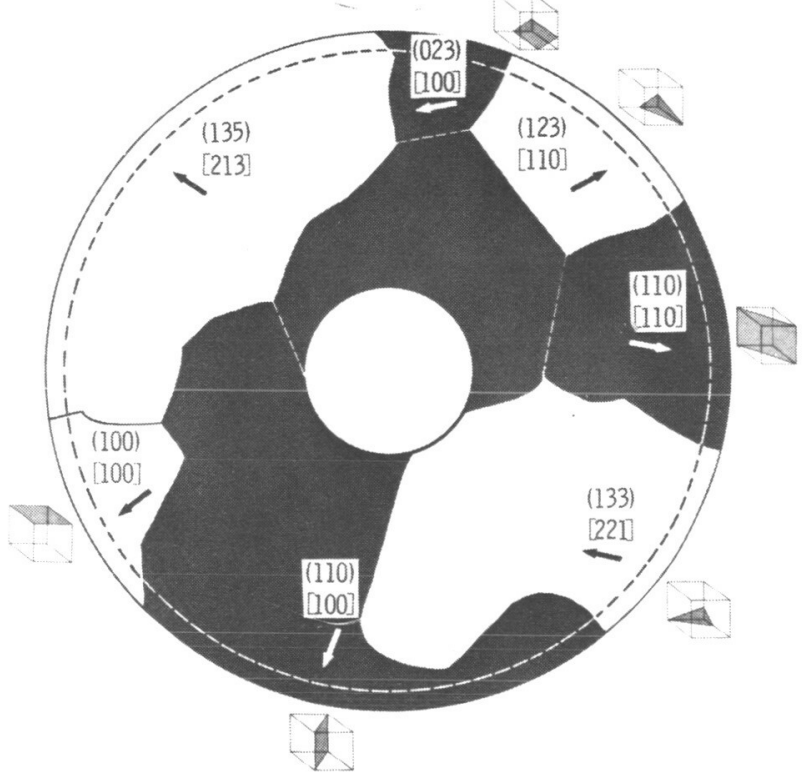

CD-8131

(a) Tungsten disk.

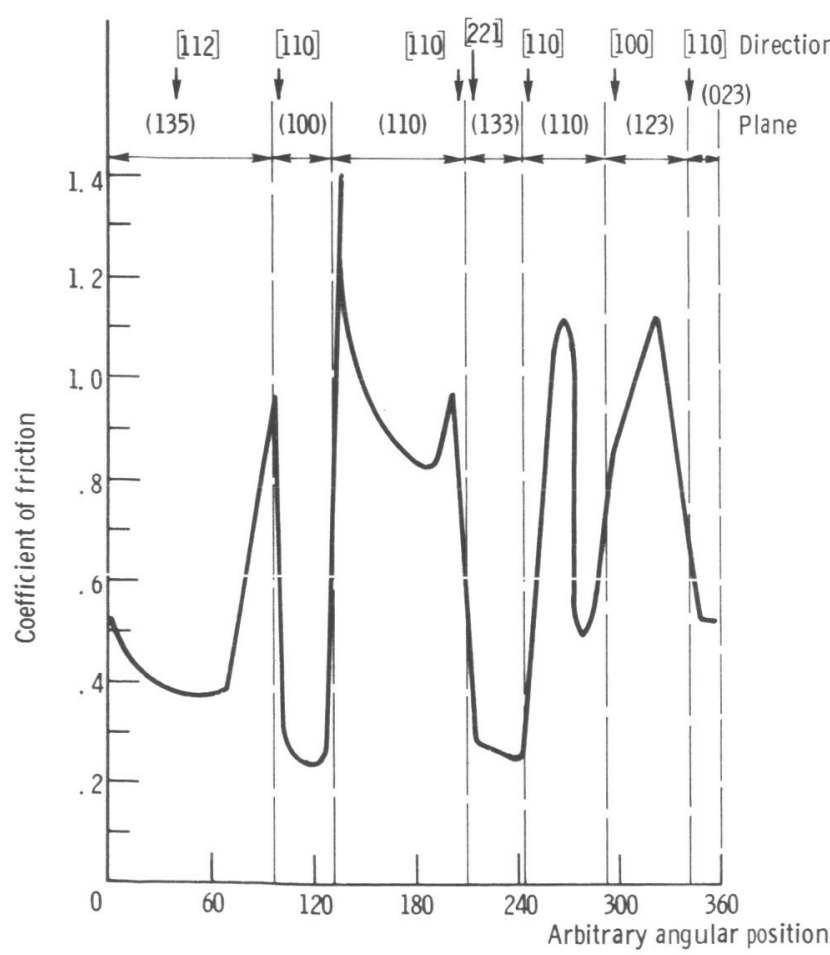

(c) In vacuum ( $10^{-10}$ Torr).

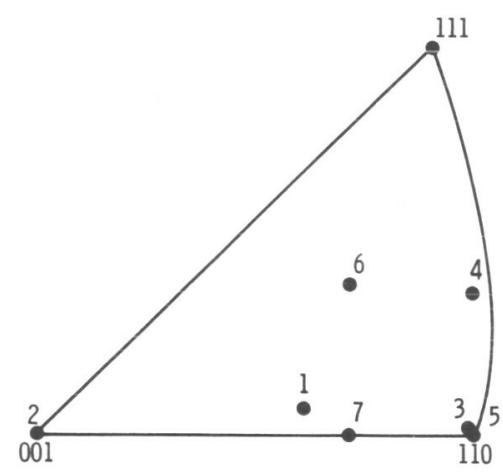

(b) Unit triangle.

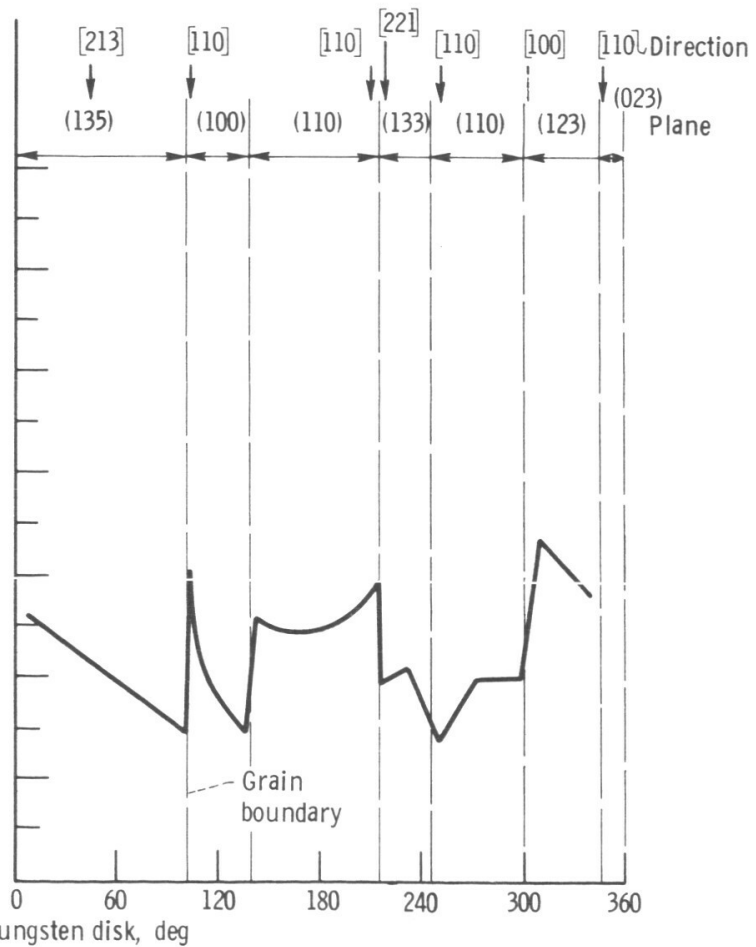

(d) In air (760 Torr).

Figure 7. - Coefficient of friction of sapphire (1010) plane sliding in [0001] direction on polycrystalline tungşten. Load, 500 grams; sliding velocity, 0.013 centimeter per second; ambient temperature, $20^{\circ} \mathrm{C}$. 

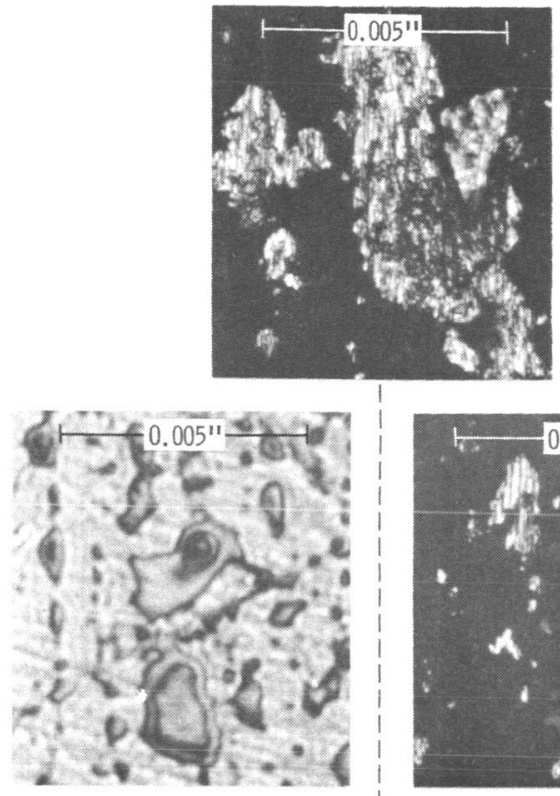

Cleavage of sapphire in contact with Be

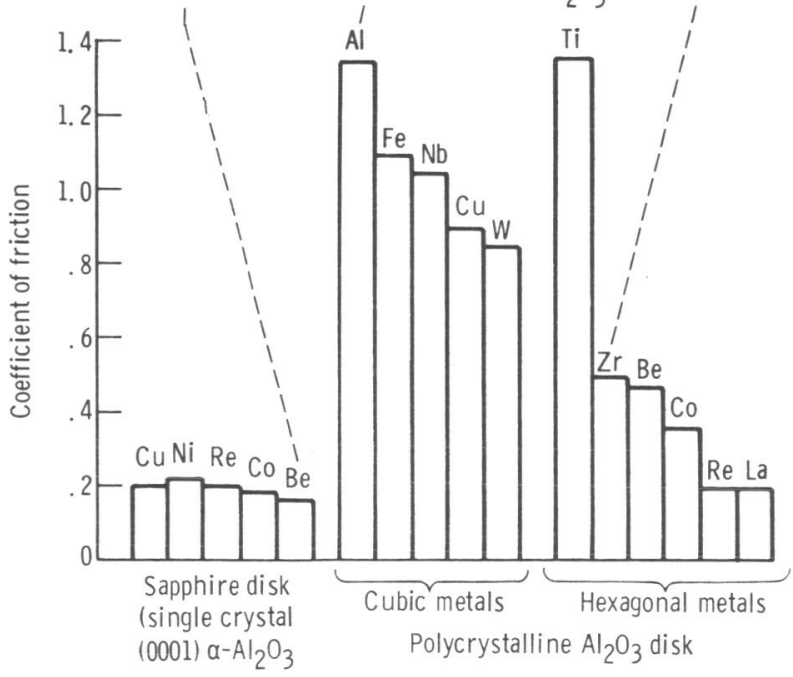

Figure 8. - Coefficient of friction for various metals sliding on a!uminum oxide in vacuum (10-10 Torr). Load, 1000 grams; sliding velocity, 0.013 centimeter per second; duration of experiment, 1 hour. 